\title{
PRODUZINDO EDUCAÇÃO ÉTICA COM DELEUZE EM ESCOLA MUNICIPAL DE EJA
}

\author{
PRODUCIENDO EDUCACIÓN ÉTICA CON DELEUZE \\ EN UNA ESCUELA MUNICIPAL DE EDUCACIÓN PARA \\ JÓVENES $\Upsilon$ ADULTOS - EJA \\ PRODUCING ETHICAL EDUCATION WITH DELEUZE \\ AT A BRAZILIAN MUNICIPAL SCHOOL FOR \\ YOUTH AND ADULT EDUCATION - EJA
}

Fernando Yonezawa ${ }^{1}$ e Fabio Hebert Silva ${ }^{1}$

${ }^{1}$ Universidade Federal do Espírito Santo, Vitória/ES, Brasil

RESUMO: Neste texto, amparados pelos conceitos de Deleuze e utilizando-nos do método cartográfico, que consiste no acompanhamento de processos de uma realidade, objetivamos compartilhar um momento de nossa pesquisaintervenção centrada na produção estética dos corpos em escolas, realizada em escola municipal de EJA. Focar-nosemos no acompanhamento do caso de uma estudante, a qual angustiava aos educadores por ser entendida como sujeito de educação especial e vítima de abuso sexual. Lançando mão da noção deleuzeana de ética para acompanhar esse caso, discutiremos como se dá a construção de uma educação ética, a qual pretende aumentar a potência de conhecer baseada na produção de encontros alegres. Veremos que a estudante pôde aprender sobre suas potências à medida que a escola, sem vitimizá-la, agenciou encontros baseados naquilo que seu corpo podia.

PALAVRAS-CHAVE: Educação; Ética; EJA; Potência.

RESUMEN: en este texto, con el apoyo de los conceptos de Deleuze y del método cartográfico, que consiste em acompañar los procesos de una realidad, nuestro objetivo es compartir un momento de nuestra pesquisa-intervención, que se centró en la producción estética de los cuerpos en escuelas, realizada en una escuela municipal de EJA. Nos centraremos en el acompañamiento del caso de una estudiante que afligía a los educadores por ser entendida como sujeto de educación especial y víctima de abuso sexual. Usando el concepto deleuzeano de ética para seguir este caso, discutiremos cómo se da la construcción de una educación ética, cuyo objetivo es aumentar la potencia del conocer basada en la producción de encuentros alegres. Veremos que la estudiante ha podido aprender sobre sus potencias a la medida que la escuela, sin victimizarla, agenció encuentros basados en lo que su cuerpo pudiera.

PALABRAS CLAVE: Educación; Ética; EJA; Potencia.

ABSTRACT: In this paper, supported by Deleuze's concepts and using the cartographic method, which consists in following the processes of a reality, we aim to share a moment of our intervention-research focused on aesthetic bodies production in schools, which was developed in a public school of youth and adult education. We focused on monitoring the case of a student, who distressed educators for being understood as a special education subject and victim of sexual abuse. Making use of the Deleuzian notion of ethics to accompany this case, in this paper we discuss the production of an ethical education, which aims to increase the power of knowing based on the promotion of cheerful gatherings. In this process, it can be noted that the student was able to learn about her potentials as the school promoted meetings based on what her body could, without victimizing her.

KEYWORDS: Education; Ethics; Youth and Adult Education; Potency. 


\section{Acompanhar uma escola, compartilhar uma experiência}

Acreditamos que toda forma de pesquisa e/ou intervenção é também uma forma de viagem, na qual se realizam muitos processos e passagens. Nossa viagem se dá no espaço de uma escola municipal de Educação de Jovens e Adultos, que se propõe a uma experiência muito singular dentro dessa modalidade. O encontro com a escola iniciou-se via e-mail por iniciativa de uma das pedagogas, que contatou o programa de pós-graduação no qual atuamos como pesquisadores em Psicologia Institucional ${ }^{1}$ centrados no problema da produção estética dos corpos em escolas - convidando os pesquisadores à possibilidade de fortalecerem os modos de cuidar das questões enfrentadas pelos educadores.

Centramo-nos, aqui, na reflexão acerca de um momento vivido nessa parceria, a saber, o caso de uma estudante entendida como sujeito de educação especial e vítima de abuso sexual. Acompanhados dos conceitos micropolíticos de Deleuze, gostaríamos de compartilhar essa experiência de intervenção para traçarmos, também, elementos do que chamamos de educação ética.

Oficialmente inaugurada em 2010, a escola é fruto de uma iniciativa de combate ao analfabetismo, voltada ao atendimento da demanda de escolarização que chegava por parte de algumas lideranças comunitárias à Secretaria Municipal de Educação. Sua proposta, realizada em parceria com o trabalho de mais de vinte anos em EJA de uma universidade federal, consiste em oferecer aos estudantes muito mais do que a alfabetização e conclusão dos estudos concernentes à educação básica. Com o objetivo de garantir o direito à educação, e compreendendo que a demanda que chegara não era apenas de trabalhadores, mas de diversos munícipes, a escola espalhou-se por 18 regiões diferentes da cidade, atendendo a um público extremamente heterogêneo em locais também muito diversos. Entre seus estudantes, encontram-se idosos em idade avançada, adolescentes, catadores de material reciclável, pessoas em situação de rua, transexuais, pessoas com deficiência ou garotos em regime de semiliberdade. São ministradas aulas nos três períodos do dia em locais cedidos pelos órgãos públicos e comunidades de bairros, para que a escola possa chegar até onde a população precisa. Vale destacar também que, apesar dessa diversidade de contextos, não há segmentação dos alunos em salas especializadas, de forma que garotos de dezessete anos estudam junto dos idosos e pessoas com deficiência, por exemplo.

Nas palavras do projeto pedagógico da escola, sua preocupação está em oferecer uma educação voltada à autonomia, liberdade e formação cidadã, no intuito de escutar os percursos e buscas dos que ali estão, não apenas no que tange à escolarização. Suas pedagogas e educadores afirmam muitas vezes que, por trabalharem com minorias, buscam garantir o direito à educação àqueles que foram afastados dos estudos pelos métodos pedagógicos clássicos, ou mesmo por violências como a homofobia e o racismo e, por isso, estão "em situação de abandono educacional".

As aulas duram até três horas por período. Esse tempo curto de estudo em sala de aula se justifica por sua proposta de educação ampla e múltipla, que vai além da sala de aula, de maneira que, durante o ano letivo, estudantes e educadores realizam pesquisas anuais sobre temas direcionados, abordando distintas dimensões da formação dos sujeitos. Pesquisam, por exemplo, sobre sexualidade, espaço público, ecologia ou racismo, para depois elaborarem intervenções, junto da população, nos espaços da cidade.

Somado a isso, as sextas-feiras são dedicadas inteiramente a reuniões de formação e estudo coletivo dos educadores, nos quais são realizadas discussões acerca de assuntos que 
propiciam uma formação transdisciplinar, politizada e crítica, instrumentalizando os profissionais para lidar com questões ligadas às diferenças etárias, homofobia, dificuldades cognitivo-motoras, sexualidade, entre outros. No intuito de favorecer o desenvolvimento dessa proposta, as aulas são dadas sempre por duplas de educadores que trabalham juntas durante um trimestre, preferencialmente de sexos diferentes e obrigatoriamente de disciplinas distintas, de modo que se faz necessário transdisciplinarizar seus conteúdos para produzir maneiras criativas de lecionar. As falas dos educadores da escola deixam isso explícito, como ocorreu com um deles durante nosso primeiro contato com eles: "Aqui, como profissionais, temos que usar a nossa... não a experiência, mas a criatividade para dar aula numa turma com alunos de dezoito anos que tem outro aluno de sessenta anos"; ou ainda outro educador que disse em reunião: "Eu nunca fui tão desafiado como professor e acho isso saudável".

Frequentando as reuniões de formação, notamos claramente que os educadores da escola consideram que o processo educacional não se restringe à vida escolar e aos saberes disciplinares, por isso procuram conhecer os desejos, os gostos, as habilidades, os problemas vividos por seus estudantes, conforme pudemos observar na proposta de um dos educadores de Educação Física de realizar uma atividade com skates, aproveitando-se de que muitos de seus estudantes adolescentes eram amantes dessa prática e que essa seria uma oportunidade dos meninos construírem a aula incluindo o aprendizado de estudantes com dificuldades motoras. Outra educadora relatou-nos sua dificuldade em produzir sentido para o exercício da escrita com estudantes idosas, dispunha do conhecimento de que as senhoras gostavam muito de cozinhar e fazer as típicas tortas capixabas, cada uma de uma maneira, então tentou valer-se desse elemento para que exercitassem a escrita, anotando as receitas; contudo, as estudantes não veem motivo para escrever, pois, criadas na cultura da oralidade, memorizam tudo muito bem.

Esta inclusão do universo existencial dos estudantes nas aulas, importante característica da proposta pedagógica da escola, será o ponto de partida da discussão central deste texto, a qual realizaremos mais adiante. Tendo apresentado um pouco do funcionamento da escola, explicitaremos na sequência a metodologia utilizada neste trabalho.

\section{Cartografia: Um modo de caminhar}

Há sempre distintos modos de se fazer uma viagem. Amir Klink, ao dar a volta ao mundo sozinho num barco, dizia que, para suas viagens, era necessário preparo extremamente rigoroso, porém, o apego aos planos durante a viagem seria letal. Em seu caminho, navegar implica mapear um novo traçado sobre o trajeto pensado. Então, um modo de realizar uma viagem é pelo que se chama de método cartográfico, o qual poderia ser nomeado a estratégia-sem-estratégia, pois nela todo preparo anterior é embaralhado e o plano navegado dissolve os planos estabelecidos.

Assim, dizem Amador e Fonseca (2009, p.33) que a atuação do cartógrafo se inicia por desfazimento e por uma disposição em desaprontar-se. Isso não aponta, porém, para uma displicência do cartógrafo, pois ele precisa se tornar sensível às ondulações da própria viagem e também àquilo em que ele próprio se transforma no navegar. Então, Alvarez e Passos (2010, p.137) chamam de "receptividade afetiva" esta abertura para os processos intensivos que acontecem no trajeto da cartografia. Trata-se, pois, de um refinado e delicado rigor. Portanto, cartografar é vasculhar o inesperado: uma política e uma prática 
do presente em mutação; o cartógrafo se coloca sempre no recomeço. Logo, cartografar é começar disponibilizando uma sensibilidade fina. Com efeito, a cartografia se preocupa em, nos dizeres de Escóssia e Tedesco (2010, p.99), desafiar-se a "investigar as formas, porém, indissociáveis de sua dimensão processual”. Ora, o trabalho cartográfico investiga o real não enquanto dado, mas como plano de forças produtivas. Exercita-se aí o "acompanhamento de processos" (Barros \& Kastrup, 2010, p.53) do real - de abertura deste para novas expressões, afetos, encontros, modos de relação - e implica-se ainda "um processo de aprendizado do próprio cartógrafo” (Alvarez \& Passos, 2010, p.135).

Foi com essa disposição que atendemos ao chamado da escola e passamos a frequentá-la, de modo a, inclusive, compormos as aulas juntamente com os educadores. Desejávamos estabelecer um "plano de experiência compartilhada", onde pudéssemos construir coletivamente formas de produção de conhecimento, tal como propõem Sade, Ferraz e Rocha (2013, p.283) sobre a atividade cartográfica.

\section{Educação ética: produzir um conhecimento das relações e dos corpos}

Estudando o tema da ética com Deleuze, descobrimos que não podemos problematizá-la sem falar dos corpos e de suas respectivas relações constituintes. É que, diz Deleuze inspirado em Spinoza, tem-se um profundo "desconhecido do corpo" tão insondado quanto o desconhecido do pensamento. (Deleuze, 2002, p. 23, grifos do autor).

Ora, cada corpo é feito de uma relação característica que é, ela própria, encontro com outro corpo: nenhum corpo é uma unidade, mas relações de corpos (Deleuze, 2010, p.190). O longo e contínuo complexo formado pelos encontros de corpos distintos e as respectivas relações mutantes é que produzem as existências, os modos de vida. Porém, nossa consciência tem apenas efeitos esparsos dos encontros. "Encontramo-nos em uma tal situação que recolhemos apenas 'o que acontece' ao nosso corpo, 'o que acontece' à nossa alma...” (Deleuze, 2002, p.25). Dito de outra forma, nosso saber está sempre em atraso em relação ao que se sucede conosco: estamos antes padecendo das transformações de um encontro do que sendo capazes de pensá-lo. Isso nos coloca em situação de não sabermos exatamente o que é nosso corpo em sua relação própria e o que é nossa alma em sua relação própria.

Já começamos a ter ideia do que seja a ética e sua relação com o corpo e com a educação: existir é incessantemente conhecer nosso corpo e sua potência, aprender sobre os encontros que realizamos e as relações que estabelecemos. Entende-se por ética o estudo daquilo que acontece aos corpos e em que se transformam nos encontros; em se tratando de um estudo, entendemos que ético é o modo de saber que admite um desconhecimento inescapável a respeito das relações. Na medida em que se parte do processo dos encontros, também já se instaura a ética como um pensar da multiplicidade. Um pensamento da navegação e da incerteza. A lógica da ética é, pois, a do não instituído, do valor não assentado, não um saber sobre os deveres, mas sobre os devires. Em outros termos, ético é o exercício de aprender sobre a multiplicidade que nos tornamos nos encontros.

Com efeito, a ética se difere muito claramente da moral, de um sistema do juízo, do senso comum e do consenso. Segundo Deleuze (1997, p.144), “o juízo se confunde com a psicologia do sacerdote" que deseja julgar, mas tira esse pressuposto poder de julgar da conjunção que faz entre a existência e a ordem do tempo, este tornado universal e imutável. A existência é, então, submetida a esse ordenamento do universal transcendente. 
O juízo lança-nos, pois, a um sistema de contratos e tabelionatos, que asseguram em tábulas os princípios segundo os quais as existências devem se distribuir, diz Deleuze (1997, p.146), em lotes merecidos conforme a relação com a transcendência sagrada. Vemos, assim, que o juízo recai necessariamente sobre indivíduos tornados corpos privados, descolados de seus encontros e relações, propriedades de um sujeito endividado, remetido a códigos de valor preestabelecidos. O corpo é, assim, feito corpo formal de um sujeito, recortado e tendo suas partes distribuídas para especialistas representantes deste saber divino-endividante: Deus-médico, Deus-psicólogo, Deus-padre, Deus-professor.

Por outro lado, a ética se substitui ao sistema de ajuizamento na medida em que não vem para dividir e endividar a vida, mas para captar problemas, linhas tensivas que constituem as incertas relações de corpos. Dessa forma, a atividade ética consiste em problematizar as potências e não em condená-las ou salvá-las, dizê-las corretas ou errôneas. "O que nos incomodava é que, renunciando ao juízo, tínhamos a impressão de nos privarmos de qualquer meio para estabelecer diferenças entre existentes, entre modos de existência, como se a partir daí tudo se equivalesse" (Deleuze, 1997, p.153).

Para o autor, essa é uma questão crítica, porque cada existência será um modo de vida que porta e tem problemas consonantes com sua potência, com os afetos que secreta. Em vez de impingir formas aos corpos, a crítica ética lhes dá um conhecimento de sua potência: tarefa educativa da ética. A crítica ética, portanto, fortalece, dá um copo de potência aos corpos. Daí ela operar necessariamente na imanência dos encontros, segundo as relações e corpos aí produzidos, nunca antes deles, ou seja, a ética é a aposta num mundo a ser produzido. Enfim, enquanto a ética diferencia as vidas no tempo dos acontecimentos, a moral apenas as iguala na eternidade de um mundo morto, de formas e imagens reconhecíveis.

Deleuze ainda destaca que há uma diferença de natureza entre o conhecimento e a moral. "A lei, moral ou social, não nos traz conhecimento algum, não dá nada a conhecer" (Deleuze, 2002, p.30). O conhecimento é a "potência imanente que determina a diferença qualitativa dos modos de existência bom/mau" (Deleuze, 2002, p.31). Se as existências, segundo a moral, são determinadas a serem benevolentes ou maldosas, criminosas ou santas, a partir da ética elas podem multiplicar aberturas existenciais, que lhes trarão bons ou maus encontros. São os encontros - e não os sujeitos - que podem ser ditos bons ou maus, conforme sejam, respectivamente, compositores ou decompositores das relações.

Mas, se nosso saber a respeito dos encontros e de nosso corpo é sempre pífio, como saber se eles são maus ou bons? Estranhamente, esse conhecimento vem pela mesma precariedade que temos nesses encontros. É que os encontros entre os corpos produzem afetos, e estes são justamente os fragmentos de realidade que nossa consciência recolhe daquilo que acontece ao nosso corpo. Spinoza (2009, p.98) compreende por afeto "as afecções do corpo, pelas quais a sua potência de agir é aumentada ou diminuída, estimulada ou refreada...". Com efeito, um afeto é a afirmação de uma perfeição maior ou menor, mas entendendo que esta perfeição não é senão uma quantidade de realidade presente (Spinoza, 2009, p.152).Os afetos podem ser, então, alegres ou tristes, conforme sejam decorrentes de bons ou maus encontros. Se os encontros reduzem a quantidade de realidade apropriada pela relação formada pelos corpos, daí diz-se que o encontro foi mau. O bom encontro, por outro lado, produz, multiplica e, logo, transforma as relações; o mau encontro as desfaz, as limita, divide suas forças. Bom é o encontro que amplia a realidade dos corpos e quanto mais realidade pertence à natureza de um corpo, mais potência ele tem (Deleuze, 2010, p.78). 
Vejamos que são os afetos os elementos que nos permitem começar o trabalho ético de distinguir e construir a existência sobre relações potentes. É sobretudo na valorização das alegrias que se baseia a ética."A Ética é necessariamente uma ética da alegria” (Deleuze, 2002, p.34). Só a alegria nos traz critérios, nos torna capazes de realizar a aprendizagem. Aqui, cabe uma rigorosidade quanto ao conceito de alegria: o afeto de alegria é uma potência e, como tal, consiste numa quantidade de realidade e, mais profundamente, no aumento da capacidade de agir. Potencializar é aumentar a capacidade de agir: não é apenas sentir alegria na sua forma psicológica, mas aumentar a ação do corpo e a quantidade de realidade com que ele pode se relacionar e conhecer. Em suma, "podemos dizer que a alegria aumenta nossa potência de agir, e a tristeza a diminui” (Deleuze, 2002, p.106, grifo do autor). Assim,é a alegria que nos torna inteligentes, e não há nada de inteligente na tristeza (Deleuze, 2009, p.18).

Com efeito, Deleuze destaca de Spinoza três níveis de conhecimento, que se tornam mais potentes e abrangentes quanto mais se aproximam da força de conhecer da Natureza. Aqui, deter-nos-emos apenas no primeiro e segundo níveis de conhecimento, pois é este último que trata mais especificamente da potência de conhecer que desenvolvemos a partir dos afetos.

É preciso considerar, antes de tudo, que os modos de conhecimento são também formas de vida, "porque o conhecer prolonga-se nos tipos de consciência e de afetos que lhe correspondem" (Deleuze, 2002, p.64). A relação de corpo implica uma capacidade de ser afetado; estes são correlativos à maneira como conhecemos, como pensamos e, portanto, como vivemos. Se colocarmos um corpo a viver de maneira a padecer mais do que produzir ativamente alegrias, os afetos, o corpo e a razão aí vividos serão condizentes com essa forma de existir. Ora, sua capacidade de aprender e conhecer estará reduzida ao mínimo, pois a impotência é também redução da quantidade de realidade compreendida.

Pois bem, o primeiro nível de conhecimento é este em que nossa potência de conhecer se encontra passiva, relegada ao acaso dos encontros (Deleuze, 2009, p.11), apenas consumindo afetos, sejam eles alegres ou tristes. Nesse nível, o corpo apenas sente alegria ou tristeza, mas não se torna capaz de agir e de aprender sobre sua relação e seus encontros. Não há aí ativação daquilo que se chama de potência de conhecer. O primeiro nível de conhecimento produz um modo de existência em que o pensamento somente é capaz de repelir aquilo que o corpo sente como tristeza e apegar-se faminto àquilo que sente como alegria. Trata-se de um nível em que o corpo não se apropria da sua capacidade de selecionar os encontros, a partir do conhecimento que produz sobre as relações. A existência é levada aos trancos. Faz-se, aí, uma vida que só pode sofrer, ainda que possa sentir alegria no corpo. Nessa forma de conhecimento limitamos nossa potência afetiva, ou seja, caímos em insensibilidade, o corpo se anestesia.

Por isso, inicialmente, o afeto é tido como ideia inadequada ou afecção passiva. Essas afecções são confusas e mutiladas, colocam a mente a padecer ao invés de agir (Spinoza, 2009, p. 100). Uma afecção é nomeada passiva quando não se explica por nossa potência de conhecer, mas por nossa força de padecer apenas (Deleuze, 2010, p. 200). Dessas ideias inadequadas derivariam paixões passivas, afetos tristes, e mesmo uma alegria pode ser passiva, se não envolve nela a nossa capacidade de conhecer; uma afecção que gera paixões ativas é aquela que advém de nossa capacidade de conhecer: aí, se encontra uma alegria ativa.

Assim, num segundo nível de conhecimento, se vive um salto, uma passagem. É que, quando um encontro produz alegria, se estabelece, entre os corpos, a chamada noção comum. 
A partir delas vive-se um aumento de potência compartilhado, um aumento da capacidade de agir. Elas são o primeiro tipo de ideias adequadas (Deleuze, 2002, p.98). Acontece que essa capacidade de agir é correlativa à capacidade de pensar e selecionar os encontros, ou seja, quanto mais podemos aprender com eles, mais ativos e inteligentes nos tornamos. As noções comuns, destaca Deleuze (2009, p.18), não são abstratas: são devires, passagens, que justamente ampliam a quantidade de realidade que os corpos se tornam capazes de compreender. Ela é uma potencialização produzida por relações alegres, cuja força está em precisamente criar um novo conhecimento, um saber sobre o que se pode. Reitera Spinoza (2007, p.43): "quanto mais coisas a mente conhecer, tanto melhor compreenderá suas forças". O encontro faz com que ambos os corpos envolvidos devenham um novo corpo, uma nova potência. A noção comum, por isso, é a potência compartilhada. De forma alguma ela é igualdade. É a diferença que se faz comum.

Temos por certo que uma existência não é a existência de um indivíduo, mas sempre uma composição coletiva, sempre uma complexidade de poderes afetivos e, quando de um bom encontro, o que se cria é um corpo mais potente do que cada um sozinho (Spinoza, 2009, p.169). Pois bem, é com as noções comuns que se começa a conhecer outras maneiras de viver e a se produzir ética; elas são o início de uma metamorfose e inauguram a alegria dentro de uma existência, porque fornecem meios de tomar os afetos como elementos imanentes dos encontros, a partir dos quais se pode perceber a força de conhecer de um corpo, sua relação própria e sua correlativa potência. Aprender é, tão logo, apropriar-se dessa força de conhecer, movimento pelo qual a sensibilidade se sofistica; logo, não se está mais somente ao sabor das paixões, mas somando-se a estas como materiais de aprendizagem, uma aprendizagem para a existência, para a construção contínua de um modo de viver ativo. Ora, se os encontros não cessam nunca de nos acontecer, então o conhecimento nunca está dado e nunca estará acabado; sempre nos tornamos um novo corpo, que precisa aprender sobre suas potências.

Em suma, referimo-nos a um conhecimento necessariamente imanente aos encontros, uma aprendizagem afeita aos afetos, mas não dependente deles. Quando trazemos a noção de uma educação ética, portanto, estamos tratando de um modo de educar engajado à produção de modos de vida alegres, potentes e ativos, preocupados com a aprendizagem a respeito das relações, necessariamente envolvendo os afetos e potências nelas constituídos.

Findada a explanação conceitual, voltamo-nos, na sequência, a pensar no tipo de vida e de educação produzida na escola em que atuamos.

\section{Uma vinheta do cotidiano escolar para produzir e pensar uma educação ética}

Quando cartografamos e estabelecemos um plano de imanência, selecionamos algumas passagens e movimentos dos encontros feitos durante a viagem para podermos pensar sobre o que nos acontece, quais transformações se dão ou pedem lugar no território que habitamos. Gostamos de chamar de vinhetas as passagens que escolhemos a fim de nos debruçarmos mais minuciosamente e analisá-las, portanto, apresentaremos uma vinheta da vida educacional da escola em que atuamos.

É partindo de uma concepção de educação preocupada em incluir o acompanhamento do processo de vida dos estudantes que a demanda das pedagogas nos chegou. Após termos frequentado algumas reuniões às sextas-feiras, uma das pedagogas pediu que 
viéssemos conversar em outro momento para que, disse ela, “ajudássemos a pensar" sobre o caso de uma estudante com deficiência intelectual que suspeitavam ser vítima de abuso sexual. Prontamente aceitamos e marcamos outra data. Apesar de nos sentirmos contentes em poder contribuir com o trabalho da escola, também nos sentíamos apreensivos pelo tipo de situação que o chamado sugeria. A reunião foi entre nós, uma das pedagogas e a educadora que tinha um vínculo mais próximo com a estudante Madalena ${ }^{2}$, uma senhora de cinquenta e quatro anos que, ao chegar à escola, há quatro anos, nunca havia estudado, era completamente analfabeta e possuía, além da deficiência intelectual, graves problemas fonoaudiológicos. Porém, disseram a pedagoga e a educadora, seu desenvolvimento na escola tinha sido notável e, hoje, embora ainda possua muitos problemas para falar e dificuldades de aprendizagem, se expressa muito bem, interagindo com os demais estudantes e procurando se comunicar bastante usando também muitos gestos.

Madalena teria sofrido abuso do primo durante o banho há dois anos e, por isso, sua mãe o teria expulsado de casa. Mas, a própria estudante teria dito que, apesar da dor que sentiu, "foi gostoso". Depois, quando passamos a acompanhar suas aulas, Madalena nos contou que manteve relações sexuais por vontade própria com ele até sua mãe descobrir, por ter encontrado, esquecida no quarto, uma camisinha usada por eles. Inicialmente, a pedagoga disse que a estudante teria sido abusada por muitos homens e, apesar disso, para ela mesma, o que se passava é que estaria namorando. Tanto que, quando ficava sabendo das vidas amorosas dos supostos namorados com outras mulheres, Madalena sempre ficava arrasada. Ao perguntarmos como eram as demais relações da estudante, a pedagoga nos disse que ela vive com a mãe de 74 anos e o padrasto, o qual também tenta seduzi-la e, ao ter suas investidas negadas por Madalena, profere agressões verbais, a humilhando, dizendo ser feia e condenando-a a nunca ter ninguém. A pedagoga acrescenta que Madalena diz ter o sonho de se casar e ter filhos, tem muita vontade de namorar, "quer um homem" e sente muito desejo sexual. Diante disso, a postura da mãe, contam, é sempre a de infantilizá-la, dizendo que ela "não precisa, porque tem a mamãe".

Também perguntamos à pedagoga e à educadora o que elas mesmas sentiam diante da situação e ambas disseram que têm aprendido muito com Madalena, pois ela desafia seus lugares de educadoras, trazendo muitas perguntas relativas à sexualidade e à vida amorosa de modo despudorado, principalmente porque muito da comunicação acontece por gestos, os quais as constrangem. Nas palavras da pedagoga, Madalena a leva a "ter coragem de enfrentar algumas pautas" e faz perguntas "que puxam nosso tapete”; já a educadora diz: "fico em silêncio", porque "essas perguntas quebram as pernas" e, no caso dessa estudante, "para mim é confuso o que é abuso". "Ela pergunta o que é o amor, o que é sexo anal, se precisa usar camisinha no sexo oral”, completa a educadora. Contaram ainda que, recentemente, Madalena teria se envolvido com o pedreiro que estava indo à sua casa realizar um pequeno trabalho. Nesse momento, ficamos sabendo que Madalena sempre se insinua explicitamente para os supostos abusadores. A pedagoga conta que Madalena chama os homens para o quarto fazendo gestos de "vem! vem!" com as mãos. Também com gestos, Madalena teria contado à educadora que o pedreiro quis fazer sexo anal e, por isso, teria sentido dor.

Quando perguntamos à educadora e à pedagoga o que sentem na relação com Madalena, é porque consideramos que os sentimentos sejam linhas de afeto compositoras de modos de relação. Ora, se nos importa compreender essas situações a partir de um olhar ético, só podemos fazê-lo se pudermos conhecer os afetos que passam pelos corpos e fazem parte das suas relações constituintes. 
Diante do relato da educadora e da pedagoga, também nos sentimos, por alguns instantes,como se estivéssemos encurralados, pois muito facilmente essa história nos convocava a solucionarmos tudo apenas a partir da criminalização dos homens envolvidos, construindo uma verdadeira trama de vigilância e vitimização dos sujeitos, fazendo-os passar de instituição em instituição, de especialista em especialista, sem considerar seus anseios e questões; uma vinheta que facilmente nos remete a procedimentos consensuais. Em outros termos, trata-se de uma situação que mobiliza os registros morais que nos formam como sujeitos, cidadãos e profissionais. Agindo desse modo, porém, estaríamos nos esquecendo do trabalho ético de considerar as relações imanentes à vida da estudante e os vínculos afetivos e educacionais já existentes. Ignoraríamos, ainda, a importância de produzir, nessas relações imanentes, movimentos de cuidado e educação para com Madalena, ações de como ensiná-la a usar camisinha, falar sobre a saúde específica do corpo da mulher, sobre as violências dentro de uma sociedade machista, sobre seu direito de cuidar-se como qualquer mulher, defender-se das ofensas do padrasto etc.

Ao ouvirmos com atenção as falas da educadora e da pedagoga, de que se sentiam confusas quanto a dizer se se tratava mesmo de um caso de abuso, por nosso corpo também passava muita tensão, pois entendíamos que não nos cabia, ocupando o lugar de supostos especialistas em questões psicológicas, simplesmente emitirmos prescrições e determinarmos se de fato era, ou não, um caso de abuso. Como dissemos, o exercício ético não está em salvar as existências, mas em produzir encontros que as potencializem. Quando trazemos a necessidade de produzir uma ação ética, precisamente estamos tentando nos distinguir de um olhar moral, baseado em prescrições transcendentes, mesmo que elas sejam legais e científicas. A maneira moral de olhar é sempre baseada em pressupostos e, como tal, ignora variações, sutilezas, diferenças e singularidades de cada composição de forças e relações. A moral cria códigos de conduta, que se fazem passar por éticos e técnicos e, não sendo capazes de pensar de modo imanente, velozmente julgam e destinam, determinam e condenam. Porém, a códigos só é possível obedecer ou burlar; a possibilidade do pensar e sensibilizar-se, do criar e agir se fecha, e também o poder de se alegrar e aprender se limitam. Ora, a pergunta eminentemente ética é como chegar a ter o maior número possível de alegrias (Deleuze, 2010, p.252).

Tão logo desaceleramos os alvoroços moralizantes que nos atravessavam e nos detivemos mais sutilmente em analisar os modos de relação compositores da vida de Madalena, pudemos começar a, de fato, pensar. Enquanto achávamos que deveríamos ocupar o lugar de especialistas, só podíamos pensar como justiceiros e ter a sensibilidade paralisada: não era possível pensar em ações de cuidado e educação. Então, aos poucos, juntamente com a educadora e a pedagoga, pudemos perceber que, se havia ali alguma violação, era justamente a relação de infantilização estabelecida com a mãe, a qual não permitia que Madalena sequer se questionasse sobre sua vida amorosa e sexual. Não se trata aqui de deslocarmos para a mãe a criminalização que caberia aos homens, mas de ver que a questão não eram os sujeitos, e sim os modos de relação que se faziam abusadores, violadores, cerceadores de alegria e conhecimento, isso porque o pensar ético escapa por completo da lógica da culpabilização. No caso de Madalena, sua vida se via violada na potência de amar e se fazer amada, mas também na força de construir e experimentar relações e conhecer o que seu corpo podia diante do desejo que sente.

Mesmo que pareça razoável, do ponto de vista profissional, tomar a Madalena, logo de início, como sujeito de educação especial e vítima de abuso, é também uma forma 
de violação sutil daquilo que ela própria mostrou serem suas potências, quando busca solucionar suas angústias e dúvidas, tentando tecer relações com homens e com sua educadora mais próxima. São demonstrações claras daquilo que ela já pode, nada relacionado às suas deficiências. Ora, evidentemente, não negligenciamos ações importantes, como a denúncia ao conselho de direitos humanos, que foi devidamente realizada; graças a isso, a família de Madalena foi obrigada a construir-lhe um dormitório separado, pois, até então, ela não o possuía, ficando vulnerável às tentativas de abuso do padrasto. A denúncia fora feita pela escola também porque a mãe de Madalena não investia nela o valor de um benefício do INSS que a estudante recebe por ser deficiente intelectual. Entretanto, o que desejamos enfatizar é a importância de considerarmos a complexidade dessa situação, percebendo que ações tutelares, ao contrário do que um olhar moral facilmente faz crer, têm seus limites e não dão conta da complexidade da trama de forças que produzem uma existência que, enquanto exposta a abusos, também se coloca em situações delicadas, justamente porque teve cerceadas tantas outras possibilidades de aprendizagem, encontro, construção de critérios e experiências necessárias e desejáveis a uma vida alegre.

Com efeito, quando se circunscreve um corpo dentro de categorias já dadas, como a de deficiente e vítima, "não se permite ao sujeito uma relação aleatória ou um passeio ao longo do campo aberto que é o próprio mundo” (Souza, 2012, p. 244), veta-se a sua experimentação e a produção de um olhar despoluído sobre ele. Um olhar moral, sob uma motivação protecionista, imediatamente identifica apenas os elementos institucionalizáveis dos corpos, capturando-os juntamente com nossa sensibilidade e a possibilidade de tecer relações tão somente baseadas na "confiança na virgindade do encontro", como disse um dos educadores da escola quando discutíamos sobre os estigmas dos diagnósticos médicos. O que Madalena mostra, como disse a pedagoga no referido encontro, é que "ela é, antes de tudo, uma mulher, com seus desejos, suas vontades, sua sexualidade”.Suas dúvidas e limitações não a paralisam, nem a deixam passiva; pelo contrário, sua capacidade de agir se expressa de modo vivo. À vista disso, se debruçarmos nossa análise sobre os modos de relação constituintes da vida de Madalena e sobre como ela é ativa na produção dessas relações, veremos que ela resiste, da maneira como pode, a uma planificação de sua existência ao lugar de deficiente intelectual e vítima, limitada na fala, na possibilidade de construir relações. Ela resiste ao modo infantilizado de ser cuidada, assim como ao machismo que a colocaria sempre passiva diante da vida. No relato das educadoras, sutilezas aparecem e demonstram que a situação de abuso é, antes de tudo, um agenciamento complexo em que se cruzam inúmeros fatores, inclusive ações ingênuas de Madalena estão aí implicadas. Sua ânsia por ter relações sexuais e amorosas, combinadas com a infantilização, com a pré-suposição de sua incapacidade de socialização e circulação pela cidade, o fato de nunca ter podido estudar e ter suas dificuldades cognitivas e fonoaudiológicas trabalhadas, isso tudo compõe um campo de produção de uma existência passível a mais violações e fomenta que, a seu modo, Madalena tente encontrar um possível amante. Nesse sentido, preferimos não dizer que Madalena seja vítima, mas sim que sua existência, seu corpo, estão constituídos num campo de relações abusador, que diminui sua potência de inúmeros modos, não apenas sexualmente. Dentro disso, uma possível vitimização de nossa parte seria uma forma de, mais uma vez, construir uma relação com Madalena baseada em tristeza, incutindo uma pressuposta impotência.

Diante disso, o que pudemos acrescentar à ação da educadora foi sugerir que se buscasse retomar o vínculo da escola com sua mãe, de modo a possibilitar que ela também transformasse os preconceitos que tem sobre a filha. Além disso, pareceu-nos ser uma boa intervenção fortalecer ainda mais a capacidade da estudante de criar diferentes formas de relação 
que não só erótico-amorosas. Para além da determinação simples de que se trataria, ou não, de caso de abuso por ser Madalena supostamente ingênua e deficiente, mais que lotear seu corpo em zonas de delimitação moral, é necessário agir lá onde as relações são produzidas, ou seja, na imanência de sua trama complexa, em suas conexões e disjunções, pois "a heterogeneidade se desenvolve no bojo das conexões” (Souza, 2012, p. 247). É nos encontros não-mediados pela moral e pelos códigos salvacionistas que se pode produzir educação e relações éticas. Nada podemos pensar se apenas atuamos como justiceiros, vitimizando Madalena; afinal, a lógica moral não traz conhecimento algum, não permite que pensemos ações a partir das quais a própria Madalena possa conhecer aquilo que seu corpo pode.

Ademais, sugerimos que a educadora não se eximisse de pensar também o que para ela própria era amor ou desejo sexual, para poder dialogar abertamente com Madalena, acompanhando-a no processo de compreender diferentes e possíveis maneiras de amar, de satisfazer o desejo. São processos não tão velozes, mas que têm a força de transformar os encontros tanto da estudante quanto da educadora. Mais tarde, fomos convidados e nos dispusemos também a participarmos das aulas em que Madalena estivesse presente. Quando a conhecemos, e depois de podermos acompanhá-la por algum tempo nas aulas, sentimos o quanto uma vida de restrições a prejudicaram em muitos elementos da existência, não só no que diz respeito à sexualidade. Madalena compreende muito bem o que lhe falam, o que acontece à sua volta e as tarefas que precisa fazer durante as aulas, mas, por nunca ter podido socializar e ter sido, por toda sua vida, privada de desenvolver habilidades cognitivas e comunicacionais, nossa percepção foi a de uma mulher absolutamente lúcida e com pensamentos muito claros em seu coração, mas cerceada da capacidade de se expressar e aprender sobre as relações e os encontros. É como se houvesse um rico mundo de afetos e conexões possíveis que não tivessem meios para serem expressos, ganhar mundo e se transformarem no decorrer dos encontros.

Com isso em mente, quando de outras reuniões de formação, nas quais se abordou os desafios no trabalho de educação e cuidados com Madalena, sugerimos, por exemplo, que buscássemos em seu bairro clubes ou associações que oferecessem espaços e atividades como dança, caminhadas e jogos de que Madalena pudesse participar. Propusemos ainda, que coletássemos informações para saber se a própria instituição na qual estuda a turma de Madalena não poderia realizar uma oficina de cuidado e embelezamento, considerando-se que se trata de um centro de inclusão produtiva que oferece cursos como de artesanato e corte de cabelo.

Assim, um dos educadores acionou um amigo cabeleireiro e ofereceram a Madalena o que chamaram de "um dia de princesa". Segundo esse educador, quando chegaram ao salão de beleza, Madalena lhe teria dito, emocionada e chorando: "Você é louco! Nunca vim num lugar como esse". Tiraram muitas fotos do dia, de Madalena maquiada, unhas feitas e com tintura renovada no cabelo. A aparente ação assistencialista se mostrou, como havíamos pensado quando a sugerimos, um potente dispositivo de conexão e potencialização para Madalena, o que ficou evidente nos dias decorrentes, nos quais a estudante conversou muito com as demais colegas na escola, disse querer aprender a fazer as unhas, mostrou suas fotos e, ainda, contou ter se sentido muito bem em casa diante do padrasto que tanto a humilhava. Por tais percepções, defendemos a ideia de que apenas intervenções protecionistas são insuficientes se não promoverem também um fortalecimento das vidas, em nosso caso, se Madalena não pudesse se sentir potente e confiante de sua força.

Nesse sentido, também vínhamos instigando Madalena, quando contava-nos chorosa das ofensas do padrasto, a não apenas chamar a mãe, mas a igualmente demonstrar-lhe 
sua indignação e sua raiva, limitando-o, afastando-o e sendo agressiva se fosse preciso, isso porque, se não se produz uma potencialização da própria Madalena, as relações que a constituem e que ela própria constrói permanecerão as mesmas, mesmo estando protegida. É importante destacar que, depois dessas experiências, Madalena começou a vir sempre de unhas coloridas e bem cuidadas, além de passar a dizer que não se importava mais com o que dizia seu padrasto.

Tudo isso seriam formas imanentes de dar força a um modo de relação em processo de transformação, potencializando-o ao invés de limitá-lo e apenas protegê-lo, pois a estudante já se mostrava muito capaz de buscar encontros para ter soluções às suas questões. A partir de pequenas ações, multiplicaram-se os encontros e teceram-se mais noções comuns entre o corpo de Madalena e o mundo. Trata-se, tão logo, de uma educação voltada a acompanhar, lado a lado, os processos da existência da estudante, para aí criarem-se novos modos de relação e um conhecimento alegre, capaz de aumentar a quantidade de realidade dos corpos envolvidos. Madalena pôde certamente aprender sobre o que pode diante de uma ofensa, sobre o que pode fazer para cuidar da aparência, sobre como a escola é também lugar de cuidado, sobre seu direito de circular por lugares que toda mulher circula etc. Bem diz Gallo (2012, p.5) que "aprender é fazer com o outro, não fazer como, imitar o outro".

Acreditamos que aqui temos um processo educacional, no qual se está agindo sobre a formação de uma existência em suas relações constituintes, e não apenas sobre um aparelho cognitivo, incutindo conteúdos disciplinares. Aí, a aprendizagem se torna "aventura imprevisível porque deflagrada pelo contato com diferenças, com que se desestabiliza certezas" e não mais "atividade de adequação entre representações e percepções" (Vieira Silva \& Kasper, 2014, p.712). Educar para criar novas relações é, pois, um modo de produzir noções comuns, zonas de compartilhamento de potências, as quais colocam os corpos a devirem e poderem mais, afinal, "aprender é o avesso da produção do mesmo" (Gallo, 2012, p.8). Vemos claramente que a escola possui a mesma concepção e que, por isso, se propõe a acompanhar Madalena em seu processo de produzir relações, encontrar meios de conhecer sua sexualidade, um processo cujo desafio aplica-se à própria educadora que a acompanha, na medida em que precisa igualmente saber, de si mesma, o que seu corpo pode em seu modo de lidar com a sexualidade e viver o amor. Como complementa Spinoza (2007, p.57), quanto mais a mente for capaz de compreender, tanto menos dependerá de ficções para conduzir-se.

Isso posto, compreendemos que, numa educação ética, o que ocorre é a criação de encontros cuja força esteja em produzir cuidado imanente e, assim, possibilitar uma ampliação da potência de conhecer. Quanto mais potente e mais alegre for uma existência, mais elevada também será sua força de existir (Spinoza, 2009, p.168). Percebemos, aí, uma tarefa educativa menor, como diz Gallo (2013, p.8), que vai além da sala de aula física, que acontece no mais comezinho cotidiano educacional, "além e aquém de toda política educacional, de todo projeto político pedagógico" e de toda grande lei de tutela dos corpos.

Deparamo-nos, portanto, com uma educação de jovens e adultos que se propõe a ultrapassar os limites da escolarização e do acerto de contas com uma dívida histórica a sujeitos tratados como desprovidos e vitimizados; realiza-se uma educação que toma as existências a partir da sua capacidade de agir, e não a partir de categorias legais e morais, como a de vítima e deficiente; é um caminho pedagógico que considera a natureza cambaleante e indócil do aprender, já que "aprender envolve um processo sobre o qual não se tem controle, tornando-se uma aventura imprevisível” (Vieira Silva \& Kasper, 2014, p. 725). 


\section{Conclusão: Educar com a alegria no meio}

Neste trabalho, tomamos os conceitos deleuzeanos não somente como instrumentos do pensar filosófico, mas como armas usadas em função de sua força micropolítica, sua potência de transmutar e produzir realidades na imanência das relações entre corpos.

Assim, no desenvolvimento do que denominamos educação ética, nos apropriamos da conceituação de alegria para agirmos de modo produtivo e cuidadoso sobre uma situação pedagógica delicada, delicada no sentido de frágil e complicada, mas também sutil, fina e exigente de sensibilidade.

Dialogando muito brevemente com Paulo Freire, pensador da educação no qual se baseiam as práticas dessa escola, podemos dizer que as educadoras viviam uma "situação-limite", a qual, diz o autor, apresenta uma percepção crítica, um freio à ação humana que nos obriga a nos apropriarmos de nossa historicidade, nossa condição de criadores de nosso mundo para darmos "respostas transformadoras" (Freire, 1987, p.91). A situação limite é um momento que exige a produção de uma nova relação, a circunstância que pede a tessitura de uma noção comum, a qual não está dada dentro do já pensado, mas força a nossa capacidade de pensarmos o impensado. Ora, a noção comum não é abstrata ou psicológica, ela implica uma ação concreta sobre as relações e um aumento da capacidade de aprender e agir, um aprendizado que "não deve confundir pensar com reconhecer" (Santos \& Souza, 2011 , p.5) e se perfaz como produção de conhecimento daquilo que um corpo pode.

Esse aumento da capacidade de agir acontece nas relações sob efeito de uma educação que só se realiza envolvendo o sentido de alegria, algo que precisa ser dado, como afirma Paulo Freire (1996, p.142), em todo processo do educar, e não apenas como seu produto final. A alegria não é, pois, apenas um sentimento positivo e bondoso, mas uma potente ferramenta de construção de conhecimento, de crítica e transformação, bem como a educação ética é igualmente uma educação que não foge à "discussão criadora”, que enfrenta temas difíceis e que, por isso, se torna "ato de amor" (Freire, 2009, p.104).

Não nos referimos a uma educação "pautada na salvação do infante de uma vida do não-saber ... para a vida do conhecimento" (Carvalho, 2013, p.6) e, consequentemente, para a adequação social, pois educar acompanhando uma existência não é tutelar uma vida, mas colocar-se na imanência dos seus encontros, envolvendo o próprio corpo de educador em processos de transformação e descobertas. Aí, não se faz mais educação a partir do ensino, mas sim pela aprendizagem simultânea e dissimétrica em que coemergem educadores e educandos, ambos aprendizes, cada qual de potências distintas, em rompimento com aquilo que Gallo (2013, p.3) denomina "lógica do ensino como explicação, que torna o aprendiz sempre dependente de um mestre".

Numa educação ética, falamos de um modo de educar que, ao mesmo tempo, não se exime de ser afetivo e se engaja em pensar com delicadeza sobre os tipos de vida que produz. Dizemos que aí se produz um "saber autêntico", que foge de "modelos alienados" (Freire, 2009, p.107), porque produz pensamento enquanto age nas relações, transformando-as a partir da força da alegria. Numa educação ética, a alegria precisa estar no meio, precisa ser considerada vital. Só podemos produzir uma educação ética se concebermos que o processo educacional não concerne à mera aquisição de conteúdos curriculares, mas também à construção de relações que aumentem a capacidade de agir.

Reiteramos: só a alegria torna os copos mais inteligentes, só ela permite construir um conhecimento que faz do aprender um ato ético, libertador e vital. 


\section{Notas}

1 Pesquisa amparada pela CAPES por meio Programa Nacional de Pós-doutorado (2014) e pela Fundação de Amparo à Pesquisa e Inovação do Espírito Santo, edital 007/2014 - edital universal integrado de pesquisa, processo 65656431/2014.

2 Nome fictício dado à estudante para preservar sua identidade.

\section{Referências}

Alvarez, J. \& Passos, E. (2010). Cartografar é Habitar um Território Existencial. In E. Passos, V. Kastrup, \& L. Escóssia (Orgs.), Pistas do Método da Cartografia: Pesquisa Intervenção e Produção de Subjetividade (pp.131-149). Porto Alegre: Sulina.

Amador, F. \& Fonseca, T. M. G. (2009). Da Intuição como Método Filosófico à cartografia como Método de Pesquisa - considerações sobre o exercício cognitivo do cartógrafo. Arquivos Brasileiros de Psicologia, 61(1), 30-37.

Barros, L.P. \& Kastrup, V. (2010). Cartografar é Acompanhar Processos. In E. Passos, V. Kastrup, \& L. Escóssia (Orgs.), Pistas do Método da Cartografia: Pesquisa Intervenção e Produção de Subjetividade (pp. 52-75) Porto Alegre: Sulina.

Carvalho, H. M. (2013). Ciborgues e Monstros em Não-lugares: aspectos da educação em uma sociedade supermoderna. Educação: Teoria e Prática, 23(43), 5-23.

Deleuze, G. (1997). Crítica e Clínica. São Paulo: Editora 34.

Deleuze, G. (2002). Espinosa - Filosofia Prática. São Paulo: Escuta.

Deleuze, G. (2009). Cursos sobre Spinoza. Fortaleza: Eduece.

Deleuze, G. (2010). Spinoza et Le Problème de L'Expression.Paris: Minuit.

Escóssia, L. \& Tedesco, S. (2010). O Coletivo de Forças como Plano da Experiência Cartográfica In E. Passos, V. Kastrup, \& L. Escóssia (Orgs.), Pistas do Método da Cartografia: Pesquisa Intervenção e Produção de Subjetividade (pp. 92-108). Porto Alegre: Sulina.

Freire, P. (1987) Pedagogia do Oprimido. Rio de Janeiro: Paz e Terra.

Freire, P. (1996) Pedagogia da Autonomia: saberes necessários à prática educativa. Rio de Janeiro: Paz e Terra.

Freire, P. (2009) Educação como Prática da Liberdade. Rio de Janeiro: Paz e Terra.

Gallo, S. (2012). As Múltiplas Dimensões do Aprender... In Prefeitura Municipal de Florianópolis (Org.), Artigos de comunicações científicas, Congresso de Educação Básica: aprendizagem e currículo. Florianópolis, SC: Secretaria Municipal de Educação. Recuperado de http:// www.pmf.sc.gov.br/arquivos/arquivos/pdf/13 $02 \quad 2012$ 10.54.50.a0ac3b8a140676ef8aeodbf32e662762.pdf 
Gallo, S. (2013). Em Torno de uma Educação Menor: variáveis e variações. In Associação Nacional de Pesquisa em Educação (Org.), Artigos de comunicações científicas, $36^{a}$ Reunião Nacional da AMPEd. Goiânia-GO: ANPEd. Recuperado de http://36reuniao.anped.org.br/ pdfs trabalhos encomendados/gt13 trabencomendado silviogallo.pdf

Sade, C., Ferraz, G. C., \& Rocha, J. M. (2013). O Ethos da Confiança na Pesquisa Cartográfica: experiência compartilhada e aumento da potência de agir. Fractal-Revista de Psicologia, 25(2), 281-298.

Santos, V. S. \& Souza, A. V. M. (2011). Aprendência(s) Nômade(s): expressões da multiplicidade em Gilles Deleuze. In V Colóquio Internacional Educação e Contemporaneidade, Anais. Aracaju, SE: Grupo de Estudos e Pesquisas Educação e Contemporaneidade. Recuperado de http://educonse.com.br/2011/cdroom/eixo\%2014/PDF/Microsoft\%20Word\%20-\%20 Aprendencias\%20Nomades\%20e\%20Multiplicidade.pdf

Souza, R. M. (2012). Rizoma Deleuze-Guattariano: representação, conceito e algumas aproximações com a educação. Revista Sul-Americana de Filosofia da Educação, 18, 234-259. Recuperado de https:// periodicos.unb.br/index.php/resafe/article/view/4546

Spinoza, B. (2007).Tratado da Reforma do Entendimento. São Paulo: Escala.

Spinoza, B. (2009) Ética. Belo Horizonte: Autêntica.

Vieira Silva, C. \& Kasper, K. M. (2014). Diferença como Abertura de Mundos Possíveis: aprendizagem e alteridade. Educação e Filosofia, 28(56), 711-728.

\section{FERNANDO YONEZAWA \\ http://orcid.org/0000-0002-7039-8611}

Psicólogo formado pela Universidade Estadual Paulista (UNESP-Assis), Mestre em Educação pela Universidade Federal do Rio Grande do Sul (UFRGS); Doutor em Psicologia pela Universidade de São Paulo (USP) e PósDoutor em Psicologia Institucional pela Universidade Federal do Espírito Santo (UFES). Professor do Programa de Pós-Graduação em Psicologia Institucional da Universidade Federal do Espírito Santo.

Universidade Federal do Espírito Santo, Vitória, ES.

Endereço: Av. Fernando Ferrari, 514 - Vitória - ES - CEP: 29075-910.

E-mail: fefoyo@yahoo.com.br

\section{FABIO HEBERT SILVA}

\section{http://orcid.org/0000-0003-2459-5128}

É psicólogo formado pela Universidade Federal do Espírito Santo (UFES), Mestre em Psicologia pela Universidade Federal Fluminense (UFF); Doutor em Educação pela Universidade Federal do Espírito Santo; Pós-doutor em Psicologia pela Universidade Federal Fluminense (UFF). Professor Adjunto do Curso de Psicologia do Departamento de Psicologia da Universidade Federal do Espírito Santo e Professor do Programa de Pós-Graduação em Psicologia Institucional (UFES).

Universidade Federal do Espírito Santo, Vitória, ES.

E-mail: fabiohebert@gmail.com 


\begin{tabular}{|c|c|}
\hline Histórico & $\begin{array}{l}\text { Submissão: 31/01/2017 } \\
\text { Revisão: 31/10/2019 } \\
\text { Aceite: 13/11/2019 }\end{array}$ \\
\hline $\begin{array}{l}\text { Contribuição } \\
\text { dos autores }\end{array}$ & $\begin{array}{l}\text { Concepção: F.Y. } \\
\text { Coleta de dados: F.Y. } \\
\text { Análise de dados: F.Y. } \\
\text { Elaboração do manuscrito: F.Y. } \\
\text { Crítico revisões de conteúdo intelectual importante: F.H.S. } \\
\text { Aprovação final do manuscrito: F.H.S. }\end{array}$ \\
\hline $\begin{array}{l}\text { Consentimento de } \\
\text { uso de imagem }\end{array}$ & Não se aplica \\
\hline Financiamento & $\begin{array}{l}\text { Projeto de pesquisa financiado pela CAPES, via Programa } \\
\text { Nacional de Pós-Doutorado, via edital do PPGPSI-UFES de } \\
2013 \text { para pesquisadores de Pós-doutorado e pela Fundação } \\
\text { de Amparo à Pesquisa do Estado do Espírito Santo (FAPES), } \\
\text { via edital Universal Integrado de } 2014 .\end{array}$ \\
\hline $\begin{array}{l}\text { Aprovação, ética } \\
\text { e consentimento }\end{array}$ & $\begin{array}{l}\text { Foi aprovado pelo Programa de Pós-Graduação em Psicologia } \\
\text { Institucional do Espírito Santo e pelos coordenadores, } \\
\text { pedagogos, professores e estudantes da escola em que se } \\
\text { realizou a pesquisa, Escola Municipal de Ensino Fundamental } \\
\text { de Educação de Jovens e Adultos Admardo Serafim de Oliveira. }\end{array}$ \\
\hline
\end{tabular}

